\section{gestão tecnológica}

\section{Objetivos; \\ ia e tecnologia; \\ 3. Metodologia; \\ 4. Resultados; \\ 5. Consideraçöes-finais.}

\section{Barreiras e sugestões para a implantacáo dos sistemas estaduais de desenvolvimento científico e tecnológico}

\author{
Gileno Fernandes Marcelino \\ Da FEA/USP; do Programa de Administraço em \\ Cléncia e Tecnologia (Pacto) \\ Eduardo Vasconcellos \\ Da FEA/USP; do Programa de Administraç⿰丿丶万⿱⿰㇒一乂 em \\ Cléncia e Tecnologta (Pacto)
}

\section{OBJETIVOS}

O CNPq idealizou e implantou os SEDCT - Sistemas Estaduais de Desenvolvimento Cientifico e Tecnológico - com o objetivo de permitir uma melhor coordenaçấo da política de ciência e tecnologia do país, através da participação efe tiva dos estados na definiçáo, implantação e acompanhamento dessa política.

Este trabalho tem por objetivo oferecer subsídios para um eficaz gerenciamento desses sistemas, abordando as seguintes questóes básicas:

- objetivos dos Conselhos Estaduais de Ciência e Tecnologia;

- localizaçáo dos CECT na estrutura dos governos estaduais;

- barreiras para a implantaçáo dos SEDCT;

- principais sugestoes para ultrapassar essas barreiras.

Inicialmente, faz-se uma apresentaçáo dos SEDCT, mostrando sua origem, importância e principais componentes. A seguir, a metodologia de trabalho é apresenta. da. No item seguinte sáo apresentados os resultados do estudo. Finalmente, consideraçoes sto feitas sobre os principais problemas e formas de solucioná-los.

\section{NECESSIDADE DE UM SISTEMA DE CIENCIA E TECNOLOGIA}

A ciência e a tecnologia constituem a mola-mestra que impulsiona o processo de desenvolvimento económico e social. Há mais de 15 anos, Price (1965) já mostrava que as bases da riqueza dos países estavam-se deslocando da qualidade das terras de cultivo e depósitos minerais para recursos menos tangiveis: o conhecimento tecnologico. Este setor, pouco a pouco, tomava-se o principal fator de desenvolvimento, ocupando a máode-obra de maior talento.

Entretanto, há uma defasagem entre a conscientizaçấo da importancia da ciência e da tecnologia e o estabelecimento de uma política coordenada para o setor.

A área de ciência e tecnologia é formada por inúmeras atividades realizadas por organizaçoes diferentes, muitas delas subordinadas a diferentes setores governamentais e espalhadas geograficamente. Desde a elaboraf̧áo do I PBDCT (Plano Básico de Desenvolvimento Científico e Tecnologico), o Governo federal vem tentan. do mobilizar recursos e esforços para desenvolver a ciên. cia e a tecnologia em nosso país. Na realidade, os PBDCT (já estamos no terceiro) representam um detalhamento dos temas ciência e tecnologia, inseridos nos TND Planos Nacionais de Desenvolvimento - que se iniciaram com o I PND, elaborado em 1972. O PBDCT é uma tentativa de integrar esses vários componentes em um conjunto de diretrizes para uma política de ciência e tecnologia; entretanto, este esforço tem sido prejudicado por inúmeras dificuldades.

Um dos principais problemas é o elevado nível de diferenciação entre os vários estados, associados à falta de uma organizaçáo dos sistema a nível estadual. Este aspecto torna difícil o delineamento $e$ a implantaçáo de uma política global para o país como um todo, porque, se não há uma estruturaçáo adequada a nível dos estudos, torna-se difícil a efetiva participaçáo dos vários estados no delineamento, na política nacional de ciência e tecnologia e, mais difícil ainda, a implantaçáo efetiva dessa política. Assim, para que o SNDCT funcione como sistema efetivamente nacional, é necessário promover a descentralização de autoridade e atividades dentro do sistema, com a implantaça dos SEDCT (Sistemas Estaduais de Desenvolvimento Cientifico e Tecnológico).

Foi a partir de dois encontros, realizados em Natal e Manaus, em 1980, que o CNPq propôs a descentralização do SNDCT, através da criação e operacionalização dos SEDCT.

Estes sistemas têm como objetivo "a organizaçáo das atividades da área de ciência e tecnologia, sob a forma de sistema, a nível estadual, que permita transformar os objetivos e diretrizes da política de ciência e tecnologia em Planos Estaduais de Ciência e Tecnologia (PECT), os quais, articulados com a açáto nacional, decorrente do III PBDCT, comporáo realmente um Plano Nacional de Desenvolvimento Científico e Tecnológico, profundamente integrado na comunidade nacional, nos seus 
interêsses, e utilizando suas potencialidades. Dessa forma, será possível simplificar e descentralizar o processo de tomada de decisões nessa área, fortalecendo as regióes, os estados, os próprios órgáos articuladores e executores da esfera federal, nas suas funçóes de tornar realidade os programas, projetos e atividades de ciência e tecnologia, de acordo com os interesses da sociedade nacional. Complementarmente, essa descentralização, sem implicar, necessariamente e sempre, transferência de responsabilidade e encargos de uma esfera para outra, permitirá, progressivamente, aperfeiçoar a metodologia de coleta e tratamento das informaçóes que interessam aos investimentos nacionais com a atividade cientifica e tecnol6gica e evitará, ou minimizará, a duplicidade e pulverização dos recursos existentes, proporcionando sua aplicação mais racional e participativa" (CNPq Sarem, 1980). Portanto, a implantação e o fortalecimento dos Sistemas Estaduais de Desenvolvimento Científico e Tecnológico virão promover a descentralização de autoridade e atividades no SNDCT e concretizar, conforme preceitua o PBDCT (1980), "a criação de órgãos regionais e estaduais, articulados com o SNDCT, e de programas ou fundações estaduais, voltadas ao estímulo do desenvolvimento científico e tecnológico (...) determinando linhas de pesquisa voltadas para as especificidades regionais". Assim, os SEDCT devem refletir as aspiraçóes e interesses da sociedade, através de soluçóes e alternativas tecnológicas adequadas à realidade sócio-econômica local. A ênfase será dada para 0 atendimento direto das necessidades da economia regional, objetivando superar

Figura 1

Sistema de Ciência e Tecnologia a nivel estadual

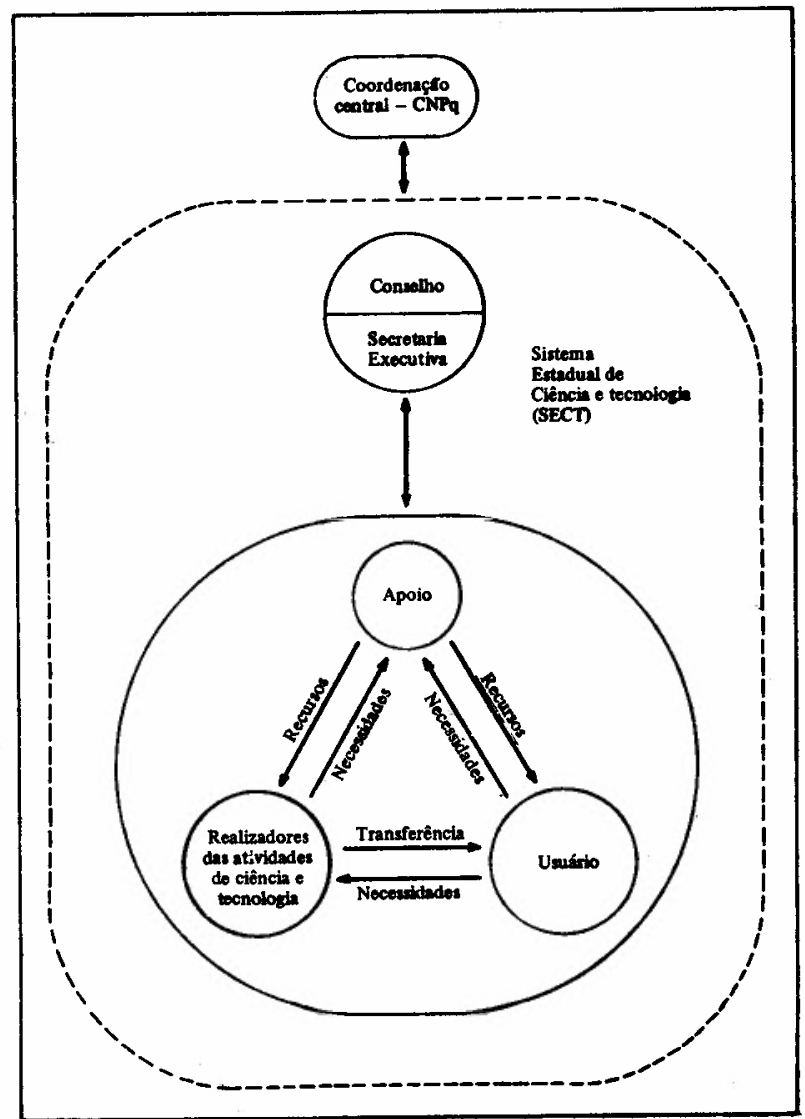

os desequilfbrios sociais e regionais. Por outro lado, procura-se, através da varíavel tecnológica, um major equilfbrio entre o crescimento econômico e 0 desenvolvimento social das unidades da Federação.

De acordo com o modelo proposto pelo $\mathrm{CNPq}$ (1981a), "cada SEDCT teria um conselho, composto por representantes dos vários setores de produçáo e utilizaçáo da ciência e tecnologia. Cada conselho teria uma secretaria executiva, responsável pelà operacionalização das diretrizes do conselho". Q CNPq promoveria $o$ fomento $e$ integraçáo entre os vários SEDCT.

Quadro 1

Os ónãos Componentes do ambiente extemo do SEDCT

Orgāos internacionais

\section{Bancos intemacionals de desenvolvimento}

Banco Mundial

Banco Interamericano

Deutsch Bank

\section{Oramizacoes mundiats}

Organizaçăo das Naçōes Unidas (Unesco, FAO)

Organização dos Estados Americanos

Organizaçto Internacional do Trabalho

Organizaçáo Mundial da Saúde

Fundaçóes e institutos de apolo a $P \& D$

Fundacão Ford

Fundação Rockfeller

Fundacão Kellog

Instituto Latino-Americano de Pesquisas Econômicas e Sociais

Massachusetts Institute of Technology

Setor privado

Confederaçōes internacionais de comércio/indústria etc.

Centros de P \& D dos grupos multinacionais

Federais

Orgdos da cúpula

Ministérios

Secretaria de Planejamento

Conseltios Federais

Sarem

Orgōos de coordenacáo e apoio de ciencia e tecnologia

Conselho Nacional de Desenvolvimento Científico e Tecnológico

Finep (Financiadora de Estudos e Projetos)

Embrapa (Empresa Brasileira de Pesquisa Agropecuária)

Capes (Coordenaçato de Aperfeicoamento de Pessoal de Nível Superior)

Sudene (Superintendência para o Desenvolvimen to do Nordeste)

Cebrae (Centro Brasileiro de A poio à Pequena e Média Empresa)

Bancos oficiats e de desenvolvimento econômico

Banco do Brasil

Banco Nacional de Desenvolvimento Econômico e Social

Banco do Nordeste do Brasil

Fundaços e institutos de pesquisa e desenvolvimento Instituto Nacional de Tecnologia

Ipea (Instituto de Planejamento Econômico e Social)

Instituto Nacional de Pesos e Medidas

Centro Técnico Aeroespacial

Fundaçäo Centro de Tecnulogia Industrial

Fitec

Universidades federais

Setor privedo

Federacóes das Indústrias, do comácio, da Agricultura etc. 
A figura 1 mostra, de forma sintética, os diversos com. ponentes do sistema estadual: os órgáos de execuçá das atividades de ciência e tecnologia, os usuários, os órgãos de apoio e fomento, o conselho como coorde. nador da política estadual ligado à coordenação central.

0 quadro 1 mostra as principais organizaçбes do ambiente externo do SEDCT. Ambiente externo to conjunto de organizaçōes que afetam (e stáo afetadas) pelos SEDCT. A dinâmica dessas organizaçóes pode ameaçar a existência dos SEDCT, assim como oferecer oportunidades para o seu fortalecimento.

\section{METODOLOGIA}

Com o objetivo de facilitar a implantação dos SEDCT, - CNPq contratou a equipe do Pacto (Programa de Administraçáo em Ciência e Tecnologia do Instituto de Administração da USP) para realizar um programa de treinamento gerencial. Este programa tinha como uma de suas finalidades a identificaçáo de barreiras à implantação dos Sistemas Estaduais em Ciência e Tecnologia, assim como sugestóes para ultrapassá-las. Os participantes deste curso seriam elementos das secretarias executivas dos sistemas a serem implantados. $O$ programa (ver Anexo 1) abordava um amplo conjunto de aspectos gerenciais, desde a definição de objetivos estratégicos até sistemas de controle de projetos.

Em cada tópico, os participantes listavam problemas e discutiam possíveis soluçбes para eles. Foram realizados dois cursos de quatro semanas cada um, totalizando 320 horas de aula e 47 participantes.

Os respondentes vieram dos nove estados da regiáo Nordeste e tinham a seguinte distribuiçæa: Maranhão (cinco), Ceará (seis), Piauí (cinco), Rio Grande do Norte (seis), Alagoas (cinco), Sergipe (quatro), Pernambuco (sete), Paraíba (cinco), e Bahia (quatro).

Quanto à formaçáo acadêmica, destacam-se com maior freqüência os graduados em economia (36\%) e engenharia (32\%), distriburdos nas áreas: agronomia, mecânica, civil, metalurgia e eletricidade. 0 s $32 \%$ restantes estavam distribuídos nas áreas de: administraçāo (8\%), pedagogia e letras (4\%), geografia (6\%), história (4\%), téc. nico em processamento de dados (2\%), geologia (2\%), qurmica (4\%) e física (2\%). Dos 47 participantes, $24 \%$ tinham mestrado concluído nas áreas de economia, engenharia e administração.

0 quadro 2 mostra a distribuiça dos respondentes em relação ao tempo de trabalho na organização do governo do estado à qual estavam vinculados e tempo no cargo atual.

Quadro 2

Perfil dos respondentes

\begin{tabular}{lcc}
\hline Tempo & $\begin{array}{c}\text { Na organização } \\
(\%)\end{array}$ & $\begin{array}{c}\text { No cargo } \\
(\%)\end{array}$ \\
\hline Menos de um ano & 8 & 8 \\
De um a dois anos & 13 & 21 \\
De dois a três anos & 16 & 21 \\
De três a quatro anos & 13 & 8 \\
De quatro a cinco anos & 25 & 17 \\
Mais de cinco anos & 25 & 25 \\
\hline
\end{tabular}

As perguntas básicas feitas aos participantes foram:

1. Quais os objetivos do Conselho Estadual de Ciência e Tecnologia (CECT)?

2. Qual a melhor localizaçáo do CECT na estrutura dos governos estaduais e qual a composiçáo de seu colegiado?

3. Quais as barreiras à implantaçáo dos Sistemas Esta. duais de Desenvolvimento Científico e Tecnológico?

4. Quais as principais sugestóes para reduzir o impacto dessas barreiras?

Cada pergunta era precedida de preleçoes conceituais com o objetivo de homogeneizar linguagem e conhecimentos. A seguir, os participantes eram divididos em grupos de acordo com o estado que representavam. 0 produto do trabalho desses grupos foi tabulado analisado para a elaboração deste texto.

Há várias limitaçóes na metodologia utilizada diferenças de nível dos participantes, elevada amplitude dos temas tratados, baixo nível de estruturaçáo das perguntas e algumas diferenças entre o primeiro e o segundo cursos. Assim, os resultados obtidos devem ser vistos como proposição para reflexão, a serem testados, com nível maior de precisđo, antes de serem aceitos.

\section{RESULTADOS}

A análise dos resultados procurará responder às perguntas-chave objeto da pesquisa inicial, agregando respostas por estado e cruzando as mais significativas.

A. Quais são os objetivos do CECT e qual deve ser a distribuição de autoridade entre o Conselho e a Secretaria Executiva, de acordo com o modelo adotado?

Pelo modelo inicialmente proposto pelo CNPq para os SEDCT (CNPq, 1981a), o Conselho Estadual, como órgáo superior de deliberação e coordenação, deveria, necessariamente, refletir o consenso do interesse governamental e da comunidade cientifica do estado. A Secretaria Executiva deveria assessorar o Conselho Estadual, através de análise e pareceres sobre projetos, consubstanciados em um Plano Estadual de Ciência e Tecnologia, ter a postura de agente central de articulação e coordenação do Sistema Estadual.

Os objetivos do CECT, propostos pelos entrevistados, estavam compatíveis com o modelo. As preferências recaíam sobre:

- definição da política de ciência e tecnologia;

- promoção da integração, articulação e coordenação dos órgãos;

- captaçáo e mobilização dos recursos humanos e financeiros para ciência e tecnologia;

- integraça a nível nacional, regional e internacional. 
Entretanto, se cruzarmos os objetivos do Conselho com as suas atribuiçбes com as atribuiçoes da Secretaria, veremos que esta compatibilidade desaparece. Estas atribuiçóes, quando analisadas globalmente, mostravam uma distinção clara entre os dois órgáos. 0 CECT estava caracterizado como um órgáo político. normativo e deliberativo; a Secretaria como um órgáo eminentemente técnico, executor de políticas, planos e programas aprovados pelo Conselho, devendo, ainda, assessorá-lo técnica e administrativamente. Entretanto, havia uma zona fronteiriça meio cinzenta entre eles, no que diz respeito a recursos. Globalmente, definiçóes estratégicas ficavam com o Conselho. Mas verifiquemos as atribuiçoes seguintes:

Quadro 3

\begin{tabular}{|c|c|c|}
\hline Orgaid & Atribuiçōes & Freqüûncia \\
\hline 늘 & $\begin{array}{l}\text { 7. Definiçāo de recursos financeiros para } \\
\text { programação e projetos de ciência e } \\
\text { tecnologia. } \\
\text { 8.Garantia de recursos financeiros } \\
\text { necessários à consecuçấo da política } \\
\text { definida }\end{array}$ & $\begin{array}{l}3 \\
3\end{array}$ \\
\hline 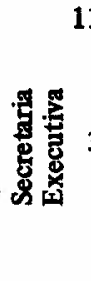 & $\begin{array}{l}\text { 11. Administração dos recursos financeiros } \\
\text { destinados a ciência e tecnologia e decisa } \\
\text { sobre sua alocaçáo aos projetos e } \\
\text { atividades especificas. } \\
\text { 3.Contatos com instituiçōes nacionais e } \\
\text { estrangeiras, públicas e privadas, para } \\
\text { cooperação técnico-financeira, e } \\
\text { intercâmbio de informaçōes científicas } \\
\text { e tecnológicas. }\end{array}$ & to \\
\hline
\end{tabular}

Três, dos quatro estados que admitiam ser a Secretaria Executiva que administrava e alocava recursos financeiros aos projetos e atividades, eram os únicos que atribuiam ao Conselho a definição do quantum de recursos para programas e projetos. Situaçáo semelhante ocorria com os outros itens em dois estados. Os demais estados, com média em torno de $50 \%$, ignoravam o problema. Este aspecto carecia de melhor definição.

Portanto, o Conselho assumia um caráter mais normativo e deliberativo do que, propriamente, de coordenaçáo, apesar de ainda dever expressar o "consenso do interesse govemamental e da comunidade cientffica e tecnológica do estado".

A Secretaria Executiva tinha a sua missáo ampliada, abarcando quase que integralmente os objetivos $(2,3,4)$ do $\mathrm{CECT}$, anteriormente citados. Existia, na prática, uma inconsistência entre os objetivos do CECT e as suas atribuiçóes.

B. Qual a melhor localização do SEDCT na estrutura dos governos estaduais a composiçáo mais adequada de seu Colegiado?

A localização do SEDCT na estrutura era, talvez, o ponto mais controvertido apurado pela pesquisa.

O Conselho Estadual tinha, como preferência da maioria, de ser vinculado ao govemador do estado - provavelmente por influencia do Sistema Estadual de Pomam- buco, que funcionava há algum tempo (desde 1977) dentro desse esquema. Esta opç⿰o vem provocando distorçóes nos objetivos iniciais do Conselho, na medida em que este está, gradativamente, se delineando como um órgto eminentemente polftico.

Quanto a Secretaria Executiva, nfo houve consenso algum. As duas preferências mais expressivas foram es. tar diretamente subordinada ao CECT (3) ou a-Secretaria de Planejamento Estadual (3); uma terceira opção (a de Sergipe), que poderia fazer pender a balança para a Seplan, era a de estar diretamente subordinada ao Instituto de Economia e Pesquisa, que por sua vez é vinculado a Secretaria de Planejamento Estadual. Isto sem falar no Maranhão, que por problemas locais adotou a soluçáo da Secretaria de Recursos Naturais, que, na prática, náo funcionou, tendo a Secretaria Executiva do SEDCT sido incorporada pelo Banco de Desenvolvimento do Maranhro.

Apesar de as opiniós estarem divididas, percebia-se, mais uma vez, a distinção entre orgáo polftico e órgáo técnico. A Secretaria tinha como uma de suas atribuiçóes assessorar técnica e administrativamente o Conselho, mas era, também, um órgto eminentemente técnico que tinha suas atribuiçóes dentro da área de influencia da Seplan.

A composição mais adequada para o CECT, conforme sugestơes apresentadas pelos entrevistados, deveria ser a seguinte:

\section{Presidente: secretário do Planejamento}

Vice-presidente: secretário da Indústria e Comércio secrétário da Agricultura secretário da Saúde secretário da Educaçæo secretário de Transporte e Obras Pablicas secretário de Energia

Representantes de: universidades federais do Estado instituição de pesquisa e desenvolvimento - exemplo: Empresa Brasileira de Pesquisa Agropecuária (CE, SE); Núcleo de Tecnologia Industrial (CE); Instituto de Desenvolvimento de Pernambuco

Codepe

CNPq

Sudene

DNOCS

Banco Oficial do Estado

Banco do Nordeste

banco de desenvolvimento do estado federação das incústrias estaduais

\section{Quais as barreiras para a implantação dos SEDCT?}

As respostas a essa pergunta foram classificadas em barreiras "intrínsecas" aos SEDCT e barreiras "extrinsecas". O quadro 4 mostra a freqüencia com que cada barreira foi citada pelos representantes de cada estado. 0 número máximo, para esta frequiència, é nove. 
Quadro 4

Barreiras intrínsecas à implantaça dos Sistemas Estaduais de Desenvolvimento Científico e Tecnológico

Choques de interesse entre os componentes do SEDCT $778 \%$

Falta de in tegraçáo en tre universidades, institutos de pesquisa, governo e sistema produtivo

Escassez de recursos humanos qualificados em ciência e tecnologia

Dificuldades burocráticas

Desconhecimento, por parte de alguns conselheiros, da realidade científico-tecnológica

Grande número de integrantes do Conselho Estadual de Ciência e Tecnologia

Não-observância das diretrizes traçadas no plano estadual de ciência e tecnologia

As três barreiras mais freqüentes foram: choques de interesse entre os componentes do sistema, falta de integração entre universidade, instituto de pesquisa, governo e sistema produtivo, e escassez de recursos humanos qualificados.

O quadro 5 mostra as barreiras extrínsecas aos SEDCT. $O$ baixo nível de prioridade para ciência e tecnologia, a escassez de recursos financeiros a pequena demanda de ciência e tecnologia foram as barreiras mais citadas. Deve-se ressaltar que a "pequena demanda" de ciência e tecnologia é, em parte, uma conseqüência da inadequação da tecnologia produzida às necessidades da regiāo. Em outras palavras, há uma demanda reprimida, que não se manifesta, e uma falta de métodos para identificá-la por parte dos órgãos "produtores" de tecnologia.

Quadro 5

Barreiras extrínsecas à implantaça dos Sistemas Estaduais de Desenvolvimento Científico e Tecnológico.

Baixo nível de prioridade para ciência tecnologia

$889 \%$

Escassez de recursos financeiros

$889 \%$

Pequena ou nehuma demanda de ciência e tecnologia

Excesso de tecnologia importada

Política salarial do estado

Desconfiança da comunidade e das empresas em relaçáo à ação do governo

$222 \%$

Imagem negativa em relação às pessoas e atividades de ciência e tecnologia

$222 \%$

D. Quais as principais sugestōes para reduzir o impacto das barreiras levando a uma eficaz implantação dos SEDCT?

A Figura 6 mostra uma lista de 12 sugestðes propostas pelos respondentes para facilitar o processo de implantação dos SEDCT.
Quadro 6

Sugestoes para implantaçáo dos SEDCT

Sugestões para a superação das barreiras

1. Bsforço preliminar no sentito da sensibilizaçato das entidades, informando-as da importancia do SEDCT.

2. Assegurar alta representatividade das entidades de C \& T dos estados na estruturaçato do SECT e na composigato do CECT:

3. Garantir a CECT o poder decisório sobre a alocaça de recursos financeiros às entidades de C \& T nos estados.

4. Seminários, conferéncias, programas de treinamento etc., para conscientizacio dos órgáos do sistema e da comunidade, no sentido de que a delegacto de poderes ao CECT - à Secretaria Executiva náo seja vista como poda de status e espaço pelos demais 6rgtos.

5. Sensibilizaçio dos demais ógatos, demonstrando que o CECT garantirá a alocação de recursos para projetos prioritários, evitando o desvirtuamento do processo de desenvolvimento de $\mathrm{C} \& \mathrm{~T}$, a pulverizacato de recursos e a duplicaģáo de esforços.

6. Enfase no papel do CECT como órgáo central de nogociaçío de recursos e de difusto de informaços e divulgaçáo de resultados de trabalhos, que poderáo ser de grande utilidade para o desenvolvimento de planos e programas dos demais órgáos do sistema.

7. "Pressto" do Governo federal, através do CNPq, sobre - Governo estadual para tratamento prioritário de C \& T.

8. Execução, pelo CECT, de programas de trabalho conjunto, que incluam as reivindicaçóes das entidades representadas no SEDCT.

9. Divulgaçáo ampla dos objetivos e atividades do SEDCT, com vistas a conscientizar as entidades públicas e privadas do papel do sistema para o desenvolvimento do Estado.

10. Selecionar projetos que possam ser executados a curto prazo e que afetem, positivamente, a comunidade, a fim de que esta interfira diretamente na valorizaçio de trabalhos ligados a C 8.T.

11. Aproveitamento, no CECT e na Secretaria Executiva, de pessoal treinado nos cursos patrocinados pelo CNPq/Sarem e ministrados pelo Pacto.

12. Criaçáo de oportunidades para modificacoes de natureza legal na estrutura do CECT, permitindo o aperfeiçamento do SEDCT, através de articulaçes no meio político.

\section{CONSIDERAÇOEES FINAIS}

Os resultados da pesquisa demonstraram, claramente, uma premissa subjacente, uma hipotese básica, a partir da qual a maioria das propostas foi desenvolvida. De acordo com tal premisea, a criactio e implantaçio dos 
SEDCT tinham o objetivo fundamental de descentralização-e regionalizaçáo das atividades de ciência e tecnologia no Brasil.

Assim, fica visfvel, por parte dos respondentes da pesquisa, que as soluçర̋es tecnológicas não têm caráter universal, dadas as suas estreitas relaçóes com as condiçóes demográficas, econômicas e culturais de cada regiđo.

Os resultados sugerem, igualmente, que os SEDCT venham a determinar linhas de pesquisa voltadas para as especificidades regionais, a criação de órgăos regionais e estaduais articulados com o SNDCT e, ainda, a operaça de programas e projetos de estímulo ao desenvolvimento local de ciência tecnologia. Também os mecanismos institucionais e operacionais para a estruturação e gestro desses órgaros, e/ou programas e projetos, permitem concluir, na forma como săo propostos, a mesma observância ds expectativas e ao potencial de cada estado.

Por outro lado, conforme demonstrou a análise dos resultados da pesquisa inicial, existiam dificuldades, já identificadas naquela fase do processo de institucionalização, que precisavam ser superadas para a adequada operacionalizaçáo dos SEDCT do Nordeste. Para que o processo náo sofresse solução de continuidade, as nossas recomendaçóes e consideraçóes finais, a partir da pesquisa inicial realizada em 1981 , eram as seguintes:

a) realização de uma pesquisa longitudinal, um ano apos a implantação, pois necessário fazia-se aferir o desempenho organizacional e avaliar a adequaçáo do modelo organizacional dos SEDCT, em face das modificaços es truturais e orientaçoes comportamentais implantadas;

b) realização de uma reuniæo regional para discussáo dos resultados descritos nessa pesquisa e avaliação de desempenho, para que cada estado obtivesse uma definição global e um modelo operacional dos SEDCT que consubstanciaria semelhanças regionais e diferenças estaduais;

c) proposiçáo de um programa de ação regional/ estadual em ciência e tecnologia, a ser levado aos futuros governadores para aprovação e implementaçáo;

d) cursos periódicos para desenvolvimento de recursos humanos dos SEDCT, com vistas a contínua capacitação e valorização profissional, visando à elevaçáo do desempenho organizacional;

e) apoio técnico e financeiro do $\mathrm{CNPq}$, sem patemalismo, para que os SEDCT do Nordeste tivessem condicoes de deslanchar (take-off) naquela fase de consolidaçáo dos sistemas.

Vale a pena ressaltar a importância de dar-se continuidade à pesquisa inicial, através de um estudo longitudinal que permitisse $o$ acompanhamento e a avaliaçá desses sistemas estaduais no Nordeste, um ano após sua institucionalizaçáo e funcionamento. Acreditamos que esse estudo permitiria corrigir as deficiências do modelo inicial, proposto pelo CNPq e aceito pelos estados, bem como as disfunçóes que, eventualmente, ccorreram no processo de implantacto.

\section{ANEXO 1}

Programa do curso gerencial para membros das Secretarias Executivas dos SEDCT
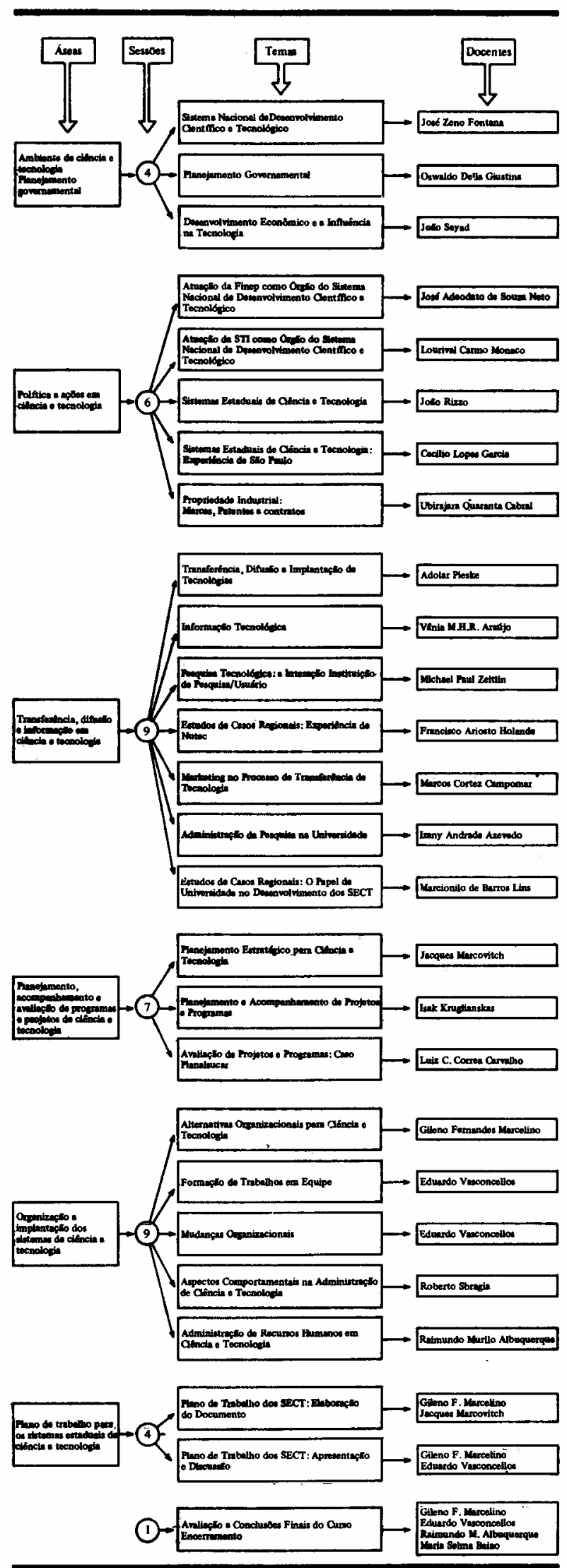


\section{ROTEIRO DA PESQUISA}

\section{PLANEJAMENTO ESTRATÉgICO}

\subsection{Objetivos do Conselho Estactual de Ciência e Tecno- logia}

- Objetivos da Secretaria Executiva do Conselho.

- Que atividades deveriam ser realizadas pela Secretaria Executiva para 0 atendimento desses objetivos?

\subsection{Ambiente externo}

- Quais os componentes do ambiente externo do consetho? Enumere as principais entidades que compoem o Sistema Estadual de Ciência e Tecnologia, assim como as entidades nacionais $e$ internacionais que estao diretamente relacionadas.

\subsection{Ameaças e oportunidades}

- Quais as principais ameaças e oportunidades que condicionam o alcance dos objetivos do CECT?

\subsection{Pontos fortes e fracos}

- Quais os principais pontos fortes e fracos do conselho na sua atual proposta de estrutura?

\subsection{Diretrizes estratégicas}

- Quais as diretrizes estratégicas a serem adotadas para alcançar os obje tivos mencionados an teriormente?

\subsection{Matriz projetos/setores}

- Qual o perfil da matriz projetos/setores a ser adotado pelo CECT do seu estado?

\subsection{Articulação com o CNPq}

- Qual o tipo de articulação a ser realizada com o CNPq $e$ as outras entidades de fomento de ciência e tecnologia para que tal estratégia se viabilize?

\section{ALTERNATIVAS ORGANIZACIONAIS}

\subsection{Localizaçăo dentro da estrutura governamental}

- Qual a melhor localizaçáo para o SECT (Sistema Estadual de Ciência e Tecnologia) em seu estado?

- A quem devem estar subordinados o CECT (Conselho Estadual de Ciência e Tecnologia) e a Secretaria Execu. tiva?

\subsection{Secretaria Executiva}

- Quais as principais funçðes que a Secretaria Executiva deve desempenhar para permitir a implantaça da estratégia?

\subsection{Composiçâo do colegiado do Conselho Estadual de Ciência e Tecnologia}

- No seu entendimento, qual a melhor composiçáo do colegiado do Conselho Estadual de Ciência e Tecnologia?

\subsection{Distribuicũo de autoridade entre o Colegiado do Conselho e a Secretaria Executiva}

- Quais devem ser as decisoes a serem tomadas pelo Conselho?

- Quais devem ser as atribuiçóes da Secretaria Executiva?

\section{ANEXO 2}

Recomendaçoes para implantaçáo dos SEDCT feitas pelos representantes dos vários estados.

À guisa de síntese, transcrevemos a seguir as principais estratégias e recomendaçðes feitas pelas equipes estaduais para implementação dos SEDCT.

\section{MARANHÃO}

- Diagnóstico elucidativo do contexto do estado em ciência $e$ tecnologia.

- Atuação do CNPq num trabalho de conscientização (sensibilização) junto aos componentes do Conselho. - Criação de um fundo de ciência e tecnologia.

- Promoção de encontros, seminários etc., junto à comunidade (universidade, órgáos etc.), com fins de identificar (dimensionar) a demanda tecnológica no estado, bem como disseminar as informaçбes sobre o Sistema.

- Criaçáo de mecanismos que consigam equiparar os salários, quando da formaçáo de equipes dos diversos órgãos do estado.

- Colocar em funcionamento o subitem 1.1 do anexo 1. - Promover formação de pessoal especializado em áreas prioritárias.

- Quanto à fase de implantação e de definiçóes de polfticas, o CNPq deverá prestar assistência a nível de consultoria. Nesta etapa, a Sarem participará com recursos financeiros, contribuindo para a viabilização do Sistema. Posteriormente, a articulaçăo com todos os órgăos de fomento dar-se-á através de programas e convênios de assistência, de apoio financeiro e de consultoria.

\section{PIAUI}

- Procurar conscientizar os membros do Conselho da importância dạ ciência e tecnologia para o desenvolvimento econômico e social do estado, através de reunioes, simpósios e palestras.

- Promover articulaçóes e integraçáo entre os membros do Conselho.

- Criar um fundo de pesquisas para o fomento de ciência e tecnologia no estado.

- Promover a interaçáo entre o govemo/universidades/ indústria/comunidade.

- Procurar integrar as instituifoes de pesquisa no estado, objetivando evitar, assim, a disperaro e o paralelismo das suas açóes. 


\section{CEARÁ}

- Dotar a Secretaria Executiva de equipes técnicas sufcientemente capacitadas - treinadas e identificadas com - ambiente de ciência e tecnologia - de modo que, por sua competência e desempenho, não sejam afetadas por mudanças administrativas (autonomia).

- Ampliar a composição do colegiado, com a participação das universidades, setor privado e órgtos nacionais e regionais que atuam em ciência e tecnologia no estado (dar assento a um ou mais técnicos da Secretaria Executiva).

- Incluir no colegiado, com direito ou náo a voto, um ou dois representantes do poder legislativo.

- Que seja mais participativo, mais sensível e que seus membros procurem divulgar, junto aos órgatos que dirigem, a importância da ciência e da tecnologia no processo de desenvolvimento do estado.

- Procurar, junto à classe política e empresarial, atravts de contatos formais ou informais, diminuir o espaco existente entre a pesquisa e o setor produtivo (maior integração).

\section{RIO GRANDE DO NORTE}

- Desenvolver um fluxograma de atividades a serem executadas.

- Desenvolver uma equipe altamente capaz de selecionar bons projetos, elaborá-los, negocít-los e acompanhá-los. Descobrir novas fontes de recursos. Fazer o marketing do Sistema.

- Concentrar todos os esforços tecnologicos para o incipiente setor industrial, já existente ou a ser instalado a curto e médio prazos.

- Pressionar os órgáos de ensino, no sentido de que des. pertem um espírito inovador na juventude estudiosa.

- Concentrar os esforços, no sentido de atender a projetos criativos, inovativos, que exijam baixos investimentos e razóaveis benefícios.

- O secretário executivo deve ser membro do Conselho. - Divulgar o sistema e sensibilizar as secretários de estado.

\section{PARAIBA}

- Entrosamento com os CECT de outros estados do Nordeste, promovendo-se o intercâmbio de experiéncia $e$ competência.

- Conseguir 0 apoio de organizacóes in ternacionais, com vistas a suprir as prováveis limitaçoes de verbas alocadas em ciência e tecnologia no estado.

- Tornar-se politicamente hábil e forte, no centido de melhor aproveitar as oportunidades que surgirto na área de ciencia e tecnologia.

- Permanecer integrado ao CNPq, com a finalidade de propor as necessidades do estado, quando das formulafóes dos PBDCT.

- Conseguir o maior número de organizaçoes estaduais de ciência e tecnologia para integrarem o SECT, usando para isto campanhas de exclarecimento, seminários e paintis, diminuindo, assim, a permanencia de grupos paralelos.
- Estreitar o relacionamento com a indústria, atraves de uma política hábil, uma vez que ela é uma forte demanda necessária para os SEDCT, procurando, inclusive, fazer uma pesquisa das necessidades tecnologicas destas empresas, visando o desenvolvimento social e econômico do estado.

\section{PERNAMBUCO}

a) quanto à composição do Conselho:

- procurar compor o Conselho de pessoas representativas de entidades que estejam diretamente vinculadas à problemática de ciência e tecnologia.

b) quanto ds atividades de planejamento/programaçáo:

- estreitar o relacionamento entre secretário executivo e o restante da equipe técnica;

- definir as diretrizes estratégicas para ciência e tecnologia (exemplo: criar comissoes para estudar os problemas de ciência e tecnologia em determinadas áreas, como na agricultura, mineração etc.);

- elaborar um programa de açáo de curto prazo, com o maior envolvimento possível das entidades de pesquisa do estado.

c) quanto d̀ melhoria de imagem do Conselho:

- divulgar, junto às instituiçóes do sistema estadual, as intençбes dos governos federal e de Pernambuco, no que tange a ciência e tecnologia (diretrizes e prioridades), através da promoçáo de palestras e seminários. Procurar tornar essas reuniбes participativas, colhendo sugestóes que possam subsidiar a elaboraçáo de programas na área.

\section{ALAGOAS}

-Q Conselho poderia captar recursos para entidades de pesquisa que desenvolvam tecnologias alternativas em energia.

- Aproveitar o.interesse federal para que se implantem, efetivamente, os SEDCT e promover simpósios, seminários etc., para sensibilização, que poderiam ser financiados pelo CNPq.

- Tentar garantir a maior autonomia possível ao Conse. lho e à Secretaria Executiva, em termos de subordinação, para que estes não sofram alteraçôs substanciais, quando das mudanças de governo.

- Tentar persuadir os futuros membros do Colegiado da necessidade de formaçáo de equipe especializada em gerência de projetos, para compor a Secretaria Executiva. - Agilizar o processo de implantação do SEDCT.

\section{SERGIPE}

- Ter como prioridade realizar o levantamento da de. manda de tecnologia, tanto no setor público como no setor privado, e, paralelamente, o levantamento dos recursos disponiveis em ciencia e tecnologia, numa tentativa de correlação necessidade versus disponibilidade. 
- Envolver a classe política, a nível dos representantes no legislativo estadual e no Congresso, a fim de que os mesmos possam defender os interesses do estado na área de ciência e tecnologia.

- Divulgar, na comunidade em geral, entre os usuários potenciais e efetivos, e nos setores técnicos, económicos e politicos, as ações em ciência e tecnologia implementadas pelo sistema.

- Dar maior autonomia possivel à Secretaria Executiva. - Fazer com que o secretário executivo seja escolhido mediante os atributos definidos no perfil.

\section{BAHIA}

- O Conselho deve ser presidido pelo governador do estado, ter o mesmo nivel de autoridade que o Cede e o Ceds e arregimentar o maior número possível de entidades de ciência e tecnologia.

- O Conselho deve ser coeso e, politicamente, ativo para influir e melhor aproveitar as oportunidades surgidas no cenário político.

- O Conselho deve agir, politicamente, a nível de governo, junto aos agentes financeiros, a fim de garantir o volume de recursos e sua distribuiçăo para o atingimento dos objetivos a que se propóe a SECT (no caso, a Secretaria de Estado de Ciência e Tecnologia).

- Os recursos financeiros, alocados a estado, seriam efetivados através da SECT.

- A SECT manter-se-á integrada com o CNPq, objetivando a consideraçáo das necessidades regionais na formaço dos PBDCT.

- A SECT ativará o relacionamento com o parque industrial, objetivando conhecer melhor a demanda tecnologica e obter um aliado político (carreamento de recurios pars o estado etc.).

- A SECT procurará mais apoio de mecanismos políticos internacionais, a fim de complementar os recursos existentes.
- A SECT promoverd a interacto com os SECT de outros Estados nordestinos, viabilizando o intercámbio de capacitaçio, a experiência política - o fortalecimento político regional.

\section{REFERENCIAS BIBLIOGRÅFICAS}

CNPq (Conselho Nacional de Desenvolvimento Cientifico e Tecnológico). Sistemas Estaduais de Ciências e Tecnologia: conceppäo e diretrizes operacionais. Brasilia, jul. 1981a. (Documento interno.)

nologia. Encontro de Natal. Brasflia, $1981 b$.

Sistemas Estaduais de Ciência e Tecnologia. Encontro de Manaus. Brasnia, $1981 c$.

Legislagăo. Brasilia, 1981d.

CNPq/Sarem. Sistemas Estaduais de Ciência e Tecnologia dos Estados do Nordeste. Brasnia, 1980. (Relatório téc-

Presidência da República. I Plano Básico de Desenvolvimento Cientifico e Tecnologico, Brasilia, 1972.

Presidência da República. II Plano Básico de Desenvolvi mento Científico e Tecnológico. Brasília, 1976.

Price, Derek J. de Solla. $O$ desenvolvimento da ciência. Rio de Janeiro. Livros Técnicos e Científicos, 1965.

Seplan/.CNPq. Origens e Perspectivas. Brasılia, 1981. Sistema Nacional de Desenvolvimento Cientifico e Tecnologico. Brasflia, 1982.

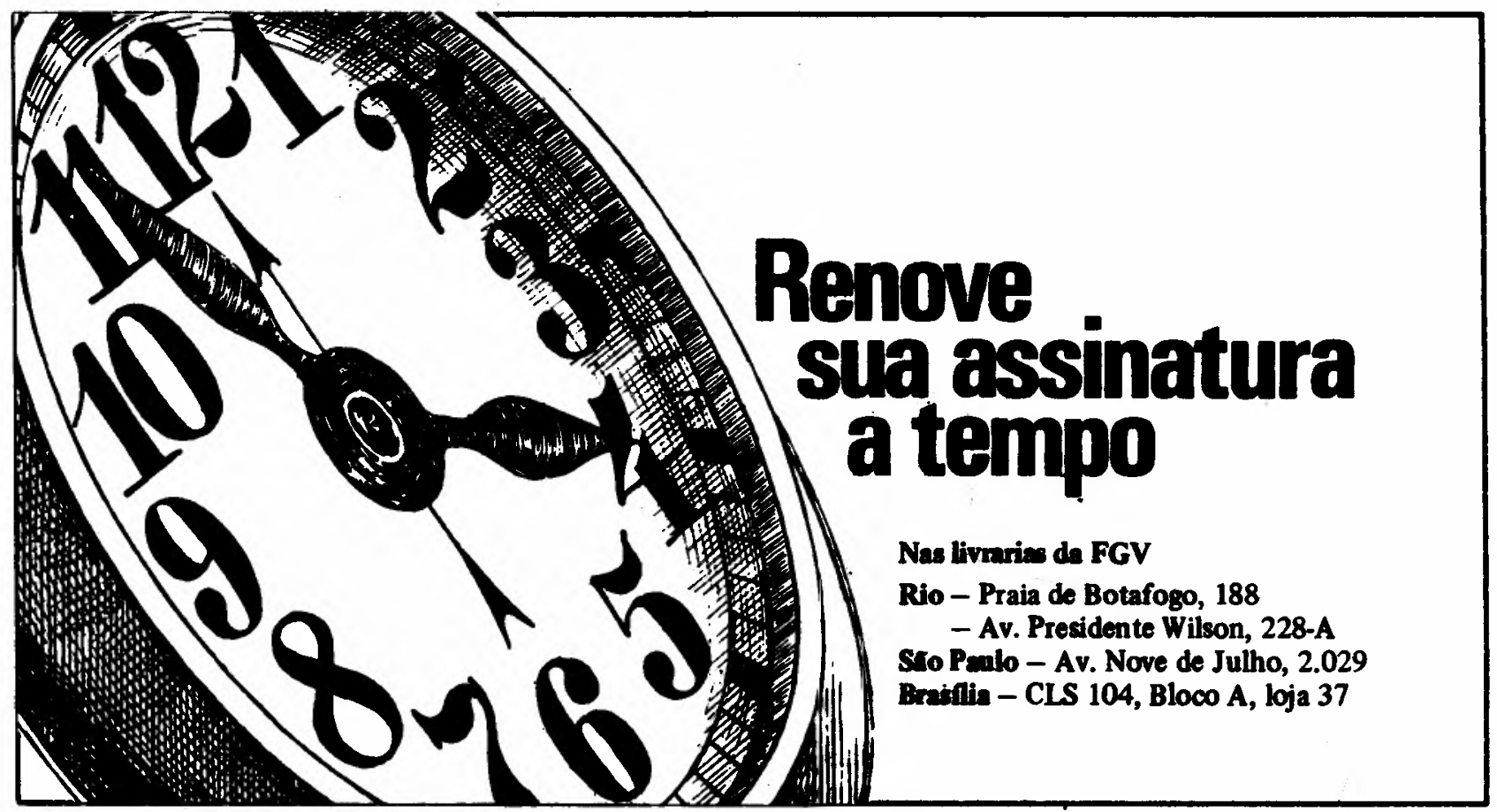

